Letter To The

\section{Editor}

Submitted: 2 Jun 2015

Accepted: 11 Aug 2015

Online: 5 Oct 2016

\title{
Isolated Intramuscular Cysticercosis
}

\author{
Beuy JoOB ${ }^{1}$, Viroj WIWANITKIT ${ }^{2}$
}

$1 \quad$ Medical Center, Sanitation 1 Medical Academic Center, Bangkok Thailand

$2 \quad$ Visiting Professor of Tropical Medicine, Hainan Medical University, Haikou, China

To cite this article: Joob B, Wiwanitkit V. Isolated intramuscular cysticercosis. Malays J Med Sci. 2016;23(5):102. http://dx.doi.org/10.21315/mjms2016.23.5.15

To link to this article: http://dx.doi.org/10.21315/mjms2016.23.5.15

\section{Dear Editor,}

The recent report on isolated intramuscular cysticercosis is very interesting (1). In this report, "a case of intramuscular cysticercosis diagnosed by ultrasonography" is presented (1). In fact, the intramuscular cysticercosis is not an uncommon parasitic infestation. In the present case, the consideration is whether this is an exact isolated cysticercosis case. Usually, the intramuscular cysticercosis is seen with the extramuscular lesion. The possible silent disseminated cysticercosis has to be looked for (2). In the present case, it can rule out only ocular and brain cysticercosis. In addition, imaging diagnosis can be a presumptive clue there can be other mimicking infections (such as sparganosis). The identification of specific scolex by imaging, as in the present case, has to be done for confirmed diagnosis.

\section{Correspondence}

Beuy Joob

MMedSc (Chinese University, Hong Kong)

Medical Center, Sanitation 1 Medical Academic Center, Bangkok Thailand

Tel: +6624658292

Fax: +6624658292

Email: beuyjoob@hotmail.com

\section{References}

1. Kanhere S, Bhagat M, Phadke V, George R. Isolated intramuscular cysticercosis: a case report. Malays $J$ Med Sci. 2015 MarApr;22(2):65-68.

2. Joob B, Wiwanitkit V. Intramuscular cysticercosis. Ann Afr Med. 2015 AprJun;14(2):122. http://dx.doi.org/10.4103/15963519.149875 